\title{
O PARADIGMA DO ESTADO DEMOCRÁTICO DE DIREITO: ESTRUTURA CONCEITUAL E DESAFIOS CONTEMPORÂNEOS
}

\section{THE PARADIGM OF THE DEMOCRATIC STATE OF LAW: CONCEPTUAL STRUCTURE AND CONTEMPORARY CHALLENGES}

\begin{abstract}
MAURICIO GODINHO DELGADO
Professor Titular do Centro Universitário do Distrito Federal (UDF) e de seu Mestrado em Direito das Relações Sociais e Trabalhistas. Ministro do Tribunal Superior do Trabalho (TST). Doutor em Filosofia do Direito pela UFMG e Mestre em Ciência Política pela UFMG. Ex-Professor da UFMG, inicialmente na Faculdade de Filosofia e Ciências Humanas (Departamento de Ciência Política) e, em seguida, na Faculdade de Direito (Mestrado e Doutorado). Ex-Professor da Faculdade de Direito da PUC-Minas (Mestrado e Doutorado).
\end{abstract}

\section{JOSÉ ROBERTO FREIRE PIMENTA}

Professor Titular do Centro Universitário do Distrito Federal (UDF) e de seu Mestrado em Direito das Relações Sociais e Trabalhistas. Ministro do Tribunal Superior do Trabalho (TST). Doutor em Direito Constitucional pela UFMG. ExProfessor da Faculdade de Direito da PUC-Minas (Mestrado e Doutorado). Integrante do Conselho Consultivo da Escola Nacional de Formação e Aperfeiçoamento dos Magistrados do Trabalho - ENAMAT.

IVANA NUNES

Mestre em Direito das Relações Sociais e Trabalhistas pelo Centro Universitário do Distrito Federal - UDF. Especialista em Direito Constitucional do Trabalho pela Universidade de Brasília - UnB (2015). Especialista em Direito do Trabalho e Processo do Trabalho pela União Pioneira de Integração Social - UPIS (2007). Graduada em Direito pelo UniCEUB (2005). Servidora pública do Tribunal Superior do Trabalho - TST. 


\section{RESUMO}

O constitucionalismo ocidental caracteriza-se pela presença de três paradigmas mais destacados. O mais antigo, denominado de Estado Liberal de Direito, originário dos documentos constitucionais do século XVIII dos EUA e da França, foi antecedido pelo pioneirismo constitucional britânico, de origem costumeira, jurisprudencial e parlamentar, desde o século XVII. No Brasil, teve influência na Constituição de 1891. O paradigma do Estado Social de Direito, oriundo dos documentos constitucionais da segunda década do século XX, como a Constituição do México, de 1917, e a Constituição da Alemanha, de 1919. No Brasil, despontou na Constituição de 1934, desenvolvendo-se também na Constituição de 1946. Por fim, o paradigma do Estado Democrático de Direito, também chamado de Constitucionalismo Humanista e Social, foi arquitetado em países da Europa Ocidental a partir de 1945/46, logo depois do término da Segunda Grande Guerra. Esses três paradigmas são estudados neste texto, com o objetivo de melhor compreender as características inerentes ao paradigma do Estado Democrático de Direito. Tal paradigma, a propósito, chegou ao Brasil apenas por intermédio da Constituição da República de 1988. O presente estudo também analisa as adversidades e os desafios que tem sido antepostos ao novo paradigma constitucional nas últimas décadas no Ocidente.

PALAVRAS-CHAVE: Paradigmas Constitucionais; O Estado Democrático de Direito como Novo Paradigma Constitucional; Desafios ao Constitucionalismo Humanista e Social.

\section{ABSTRACT}

Western constitutionalism is characterized by the presence of three main paradigms. The oldest, known as the Liberal State, arising from the constitutional documents of the eighteenth century in the United States and France, was preceded by the pioneering British constitutionalism, of customary, case law, parliamentary origins, since the seventeenth century. In Brazil, it influenced the Constitution of 1891. The Social State paradigm originated in the constitutional documents of the second 
decade of the twentieth century, such as the Mexican Constitution of 1917 and the German Constitution of 1919. In Brazil, this paradigm emerged in the Constitution of 1934 as well as in the Constitution of 1946. Finally, the Democratic State paradigm, also called Humanist and Social Constitutionalism, was designed in Western Europe from 1945/46 onwards, shortly after the end of the Second World War. These three paradigms are studied in this text in order to better understand the inherent characteristics of the Democratic State paradigm. This paradigm, incidentally, only reached Brazil through the Constitution of the Republic of 1988. The present study also analyzes the adversities and challenges faced by the new constitutional paradigm over the past decades in the West.

KEYWORDS: Constitutional Paradigms; The Democratic State as a New Constitutional Paradigm; Challenges to Humanist and Social Constitutionalism.

\section{INTRODUÇÃO}

A compreensão da estrutura conceitual do paradigma constitucional arquitetado no ocidente europeu logo depois da Segunda Grande Guerra é um dos objetivos do presente estudo. Esse novo padrão do constitucionalismo trouxe importantes inovações e conquistas em comparação com os paradigmas até então vivenciados na História.

De fato, na dinâmica do processo histórico, a positivação e universalização dos direitos e garantias da pessoa humana, embora com referências precedentes, sedimentou-se, essencialmente, nas constituições da Europa Ocidental seguintes à Segunda Guerra. A partir desse momento político, filosófico e jurídico fundamental é que se passou a compreender o ser humano em um sentido estrutural e, até mesmo, universal, como centro da ordem jurídica nos respectivos Estados e como cidadão do mundo.

É objetivo também do texto examinar as adversidades e os desafios que vêm se antepondo ao paradigma do constitucionalismo do Estado Democrático de Direito nas últimas décadas, muitas vezes colocando em questão o caráter 
democrático e inclusivo desse modelo de estruturação da sociedade política e da sociedade civil no mundo ocidental.

Para tanto, o estudo procurará retomar a análise dos dois paradigmas pioneiros do constitucionalismo, seja o do Estado Liberal de Direito, seja o do Estado Social de Direito.

De um lado, examinando as conquistas e características de cada um desses dois paradigmas constitucionais. De outro lado, indicando as suas limitações e impasses, respeitadas as peculiaridades de seu tempo histórico.

O artigo buscará, por fim, investigar a presença do paradigma Estado Democrático de Direito no Brasil, aqui consagrado por intermédio da Constituição da República de 1988.

\section{OS PARADIGMAS DO CONSTITUCIONALISMO}

\subsection{CONCEITO PRELIMINAR: A CONFORMAÇÃO DO PARADIGMA}

Para compreender a definição de paradigma na visão epistemológica contemporânea, torna-se necessária a análise da concepção construída por Thomas Kuhn. Para o autor, paradigma representa um modelo ou padrão apreendido em determinado contexto histórico, que irá servir como parâmetro para a compreensão da realidade, com sua dinâmica e seus problemas. Não se trata de um padrão monolítico, mas de um conjunto sistêmico de fatores e peculiaridades, organicamente vinculados, que se torna apto a melhor iluminar a compreensão ou a pesquisa acerca de certa relevante experiência ou fase histórica. Assim expõe Thomas Kuhn (1998, p.13): "Considero 'paradigmas' as realizações científicas universalmente reconhecidas que, durante algum tempo, fornecem problemas e soluções modelares para uma comunidade de praticantes de uma ciência".

A mudança de paradigma implica, necessariamente, que os termos, conceitos e experiências preexistentes foram redimensionados, de forma a questionar padrões anteriores e permitir que o novo paradigma seja visto como um implemento do antigo, com o acréscimo de conceitos inovadores. A crise provoca 
uma proliferação de versões do paradigma, enfraquece suas regras de resolução e permite o surgimento de um novo paradigma.

É por isso que uma nova teoria, por mais particular que seja seu âmbito de aplicação, nunca ou quase nunca é um mero incremento ao que já é conhecido. Sua assimilação requer a reconstrução da teoria precedente e a reavaliação dos fatos anteriores. Esse processo intrinsecamente revolucionário raramente é completado por um único homem e nunca de um dia para o outro (KHUN, 1998, p.26).

A noção de paradigma, segundo Menelick de Carvalho Netto, apresenta um duplo significado. Por um lado, identifica-se por momentos de ruptura no processo de desenvolvimento científico, mediante a "tematização e explicitação de aspectos centrais dos grandes esquemas gerais de pré-compreensões e visões-de-mundo", consubstanciados nas práticas sociais:

[...] que a um só tempo tornam possível a linguagem, a comunicação, e limitam ou condicionam o nosso agir e a nossa percepção de nós mesmos e do mundo". Por outro lado, o paradigma "também padece de óbvias simplificações, que só são válidas à medida em que permitem que se apresentem essas grades seletivas gerais pressupostas nas visões de mundo prevalentes e tendencialmente hegemônicas em determinadas sociedades por certos períodos de tempo e em contextos determinados (CARVALHO NETTO, 1999, p.476).

Os paradigmas, embora traduzam um conjunto orgânico formado de múltiplos fatores e aspectos, assumindo certa singularidade e, nessa medida, estabelecendo clara ruptura com o paradigma precedente, também se mostram carregados de aspectos e características que estiveram presentes no paradigma anterior. Nesse quadro, denotam uma ruptura importante, sistêmica, de qualidade, porém não uma ruptura plena, completa, atingindo todos e quaisquer aspectos.

Conforme se sabe, a verdade científica não é absoluta, pois não somente os objetos dos estudos científicos podem sofrer modificações, como também, é claro, as próprias teorias podem ser alteradas - como de fato acontece ao longo da história da humanidade. Dessa maneira, é necessário considerar o aspecto cíclico dos paradigmas, uma vez que eles se sustentam de acordo com o momento histórico vivenciado. Em conseqüência, não existe um modelo paradigmático estanque. 
No exercício de capturar a inconsistência e a imprecisão dos conceitos preestabelecidos no paradigma anterior, questionam-se e se desestruturam os seus componentes e o seu próprio centro, para só depois se consolidarem os preceitos do novo paradigma, como uma espécie de antítese inclusiva. Desconstrói-se para se reconstruir, em abandono ao conceito de verdade absoluta ${ }^{1}$.

Assim, conforme exposto, os paradigmas que se sucedem não são necessariamente antagônicos nem excludentes; ao contrário, suplementam-se a partir do momento em que, ao questionarem os conceitos tradicionais, não os negam, cuidam apenas de substituir antigos parâmetros de acordo com o atual contexto histórico, estabelecendo um novo centro para a estrutura epistemológica. O novo paradigma, conforme exposto, desconstrói o centro de referência do antigo para reconstruí-lo.

No âmbito do Direito, o paradigma permite relacionar conceitos que se sucedem ao longo da história com a realidade social. Pode, assim, ser identificado como o constructo $^{2}$ sócio-cultural que se apresenta em movimento dinâmico, pendular, estruturalmente caracterizado por avanços e recuos, fluxos e refluxos, que emergem e submergem de acordo com a ampliação e restrição de direitos no conteúdo normativo vigente. O paradigma também envolve uma mudança substancial, ou seja, de estrutura, na arquitetura do campo jurídico enfocado, embora não se trate, como dito, de uma ruptura absoluta.

\footnotetext{
1 A desconstrução aqui mencionada integra o pensamento de Jacques Derrida, ao questionar a filosofia e as construções binárias da linguagem. Para Derrida, a desconstrução epistemológica não significa destruição, e sim decomposição dos elementos já estruturados, deslocando-os do seu centro, para reescrevê-los de outra forma. Segundo ele, os conceitos sofrem transformações, e isso é tanto inevitável quanto necessário. DERRIDA, 1997 p. 101-123. A desconstrução de Derrida é voltada à linguagem e à filosofia, aos paradigmas culturais, portanto. Não seria demasiado aplicá-la também à característica cíclica e não excludente dos paradigmas do constitucionalismo contemporâneo que serão aqui demarcados, na expressão de que nenhum contexto exclui outros contextos preexistentes, e sim os redimensiona.

${ }^{2}$ A expressão é empregada na obra de Jacques Derrida (1997).
} 


\subsection{OS GRANDES MARCOS DO CONSTITUCIONALISMO E SEUS PARADIGMAS REFERENCIAIS}

Historicamente, pode-se falar em três marcos do constitucionalismo ocidental: o Estado Liberal de Direito, o Estado Social de Direito e o Estado Democrático de Direito.

É bem verdade que há autores que preferem enxergar apenas dois únicos marcos estruturais do constitucionalismo, o Estado Liberal de Direito e o Estado Social - este iniciado no constitucionalismo inovador da segunda década do século XX na Europa (Alemanha, 1919) e nas Américas (México). Tal marco teria aberto importante senda de superação do liberalismo primitivo - o que é verdade -, tendo, porém, apenas se aprofundado logo em seguida ao final da Segunda Grande Guerra, particularmente em países europeus ocidentais.

Contudo, parece mais rico e acertado, do ponto de vista científico - isso é, sob a perspectiva fática, teórica e, inquestionavelmente, heurística ${ }^{3}$-, enxergar-se uma sucessiva diferenciação nos paradigmas que superaram o liberalismo primitivo, quer dizer, o Estado Social de Direito (identificado a partir das Constituições do México, de 1917, e da Alemanha, de 1919) e o Estado Democrático de Direito, este identificado a partir das Constituições da Europa Ocidental imediatamente seguintes à Segunda Guerra Mundial (França, de 1946; Itália, de 1947; Alemanha, de 1949). É o que insiste, por exemplo, Mauricio Godinho Delgado, ao sustentar a presença de alterações substantivas - de qualidade, extensão e profundidade - entre o segundo paradigma do constitucionalismo e o paradigma arquitetado na Europa logo depois da Segunda Grande Guerra (o paradigma do Estado Democrático de Direito) (DELGADO, 2012, p.31-54).

Gabriela Neves Delgado ressalta, com propriedade, que, no curso da História Contemporânea, um modelo de Estado (e de constitucionalismo) supera o outro dialeticamente, aperfeiçoando-o (DELGADO, 2012, p.25). Quer a autora significar, naturalmente, a ideia de superação enquanto modelos, paradigmas ressalte-se -, ao invés de superação seqüencial na evolução histórico-temporal.

3 A ideia de heurístico, para as Ciências, inclusive as Ciências Sociais, traduz a noção de potencialidade de hipóteses, de maneira a descortinar maior riqueza e sofisticação de correlações procedimento, conforme se sabe, inerente e fundamental para o conhecimento científico. 
De fato, fica claro que, em distintas experiências históricas - especialmente nas posteriores às europeias ocidentais originárias (Grã-Bretanha e França, particularmente) -, os paradigmas não observaram a mesma evolução ou sequência histórico-temporal (a Alemanha, por exemplo, após unificar-se como Estado Nacional em 1871, não chegou a experimentar, efetivamente, um Estado Liberal de Direito; na América Latina, igualmente, a sequência histórico-temporal de paradigmas não é também tão manifesta e uniforme no interior de seus diversos Estados componentes).

Mas, por outro lado, enquanto paradigmas estruturantes do Direito, das instituições e da própria civilização, essa superioridade mostra-se bastante consistente e, até mesmo, óbvia. Assim, em linha de sofisticação e de complexidade crescentes, na base tem-se o Estado Liberal de Direito; em segmento intermediário, mais abrangente e inclusivo, em comparação com o paradigma anteriormente mencionado, o Estado Social de Direito; e, de maneira clara, em plano mais complexo, sofisticado e superior aos dois referidos, o paradigma do Estado Democrático de Direito.

\subsubsection{O Estado Liberal de Direito}

O paradigma liberal originário se funda na então inovadora ideia de império da lei ou do Direito (rule of law), império da norma jurídica, em contraponto à prática e à ideia de império da vontade do soberano estatal, típicas da fase histórica recém vivida na Europa, consubstanciada no absolutismo monárquico. Com essa noção inovadora de prevalência da lei, consagra-se também a ideia de controle do poder monárquico e de controle do próprio poder do Estado. A essas ideias correlatas irá se agregar a diretriz jurídica, institucional e filosófica também harmônica do absenteísmo estatal. O absenteísmo estatal no tocante às relações privadas de poder (relações socioeconômicas, inclusive as trabalhistas, a par de outras relações sociais) foi, dessa maneira, também característica marcante do paradigma do Estado Liberal de Direito.

O paradigma liberalista originário vigorou a contar da segunda metade do século XVII na Grã-Bretanha e da segunda metade do século XVIII na França e nos 
EUA, estendendo-se, hegemonicamente, por longo período no Ocidente, até as primeiras décadas do século XX. Nesse quartel, institucionalizaram-se as primeiras liberdades individuais (de opinião, de locomoção, de informação, de contratação), os primeiros direitos políticos (o direito de votar e de ser votado, o direito de eleger e contar com certa representação política no Estado, o direito de constituir e participar de partidos políticos), além das primeiras liberdades públicas (de reunião, de associação, de manifestação coletiva).

Todo esse conjunto de ideias, propostas e direitos forma o paradigma liberalista originário do constitucionalismo ocidental.

Não obstante, tal paradigma liberalista primitivo iria se mostrar, com o passar do tempo, um instrumento de sedimentação e de incentivo à desigualdade, a par de se evidenciar excludente de largos segmentos populacionais integrantes dos respectivos Estados e sociedades.

É que tais liberdades e direitos consagrados pelo liberalismo originário mostravam-se gravemente circunscritos às elites socioeconômicas da época. Quanto aos direitos políticos, por exemplo, apenas os proprietários detentores de um determinado patamar de renda (a par de, eventualmente, outros atributos restritivos) poderiam os exercer. O voto, diga-se de passagem, era não apenas censitário como também essencialmente masculino. O liberalismo originário pregava também o trabalho livre - o que constituía um grande avanço perante o trabalho servil e/ou escravo, reconheça-se -, embora, naturalmente, para esse liberalismo, se tratasse de trabalho livre sem qualquer tipo de proteção e garantias jurídicas.

Se não bastasse, o absenteísmo estatal quanto à regência das relações privadas de poder conferia ampla dominância aos segmentos proprietários privados no contexto da sociedade civil, em suas variadas dimensões (inclusive a socioeconômica, particularmente a trabalhista), estendendo-se também, evidentemente, ao contexto da sociedade política, isto é, do Estado e suas instituições ${ }^{4}$.

\footnotetext{
${ }^{4}$ Sobre os modelos de Estado e do constitucionalismo, com os seus paradigmas (Estado Liberal de Direito, Estado Social de Direito e Estado Democrático de Direito), a par dos avanços e recuos na marcha histórica e no imaginário do Ocidente, remete-se à leitura da seguinte obra dual: DELGADO; DELGADO, 2012a, especialmente em seus três primeiros capítulos, dedicados, em seu conjunto, a essa temática.
} 
O Estado Liberal de Direito representou, desse modo, o primeiro paradigma constitucional. Nesse contexto socioeconômico, o ordenamento jurídico consagrou direitos individuais, também denominados direitos de primeira dimensão, com alicerce teórico na autonomia da vontade, na liberdade de contratação e na propriedade privada. Ao Estado, não era permitido nenhum tipo de intervenção na economia - salvo as necessárias para garantir o próprio estuário liberalista, é claro. As garantias e os direitos restringiam-se ao âmbito individual e, em face de seus parâmetros excludentes, os beneficiários da ordem jurídica eram, essencialmente, os proprietários.

Esse paradigma primitivo se enquadrou nos marcos do estrito (embora então inovador) liberalismo político, econômico e filosófico. Caracterizou-se por evidente separação entre os espaços público e privado. A separação dicotômica era garantida pelo próprio Estado que, diante do império das leis, fazia prevalecer 0 estrito exercício da legalidade. Institucionalizou-se, portanto, conforme exposto, a ideia de submissão ao império da lei (rule of law). Por sua vez, as normas positivadas alcançavam apenas garantias individuais: a liberdade individual, a autonomia contratual, a proteção da propriedade privada. Nessa medida, o então império da lei consistia, na prática, no império da desigualdade e da exclusão socioeconômicas, a par da exclusão política e também civilizatória ${ }^{5}$.

Esse paradigma constitucional - guardadas as devidas singularidades do Brasil, na época - expressou-se na primeira Constituição Republicana Brasileira, promulgada no século XIX, em $1891^{6}$.

\footnotetext{
${ }^{5}$ A exclusão ora descrita, nos marcos do Estado Liberal de Direito, era realmente bastante ampla. Englobava todos os pobres, a grande maioria dos trabalhadores (pobres ou não), as mulheres em geral, a larga maioria das crianças e adolescentes, a par de outros segmentos sociais. Se não bastasse, o liberalismo primitivo convivia com algumas óbvias e graves contradições: a mais gritante delas era a mantença da escravidão nas Américas, inclusive nos EUA, embora o trabalho livre e a livre contratação fossem postulados tidos como relevantes no paradigma constitucional vigorante.

6 O País, conforme se sabe, em fins do século XIX sequer ostentava uma economia industrial, sendo caracterizado, basicamente, por um sistema produtivo agrário, com a ampla prevalência rural de sua população. Mas, por influência política e cultural norte-americana, incorporou aspectos evidentes do primeiro paradigma do constitucionalismo.
} 


\subsubsection{O Estado Social de Direito}

No plano dos países líderes do capitalismo, o fato é que o impacto da industrialização (Revolução Industrial, deflagrada na Grã-Bretanha no século XVIII e generalizada para a Europa Continental logo a seguir e, mais à frente, para os EUA) gerou graves desequilíbrios sociais e econômicos em decorrência da exploração ostensiva da força de trabalho. Por sua vez, as condições desumanas e degradantes a que estavam submetidos os trabalhadores contribuíram para o surgimento, entre estes, de uma consciência a respeito de seus interesses comuns (então denominada "consciência de classe"). A solidariedade entre os indivíduos colocados em condições semelhantes de trabalho acabou por dar origem à identidade coletiva dos trabalhadores e ao corolário fenômeno do sindicalismo, que se estruturaram, com crescente força, ao longo do século XIX, especialmente na Europa Ocidental.

Passados os primeiros tempos de existência do capitalismo industrial (da revolução econômica no século XVIII até o início do século XX), ficou cada vez mais claro que o capitalismo e seu liberalismo originário tinham sido capazes de produzir bens e riqueza, mas fracassaram na estruturação de um sistema razoavelmente igualitário e justo para todos (ou, pelo menos, para a grande maioria da população).

Pressionado pela emergente e contínua organização dos setores populares e pela própria necessidade de sobrevivência do sistema capitalista - que estava na iminência de uma violenta ruptura, em processo autofágico de destruição -, o paradigma liberalista primitivo teve de ceder lugar ao paradigma do Estado Social de Direito, marcando a mudança da primeira para a segunda dimensão do constitucionalismo.

A falta de compromisso do Estado Liberal com a dimensão social das relações, problemas e desafios da vida socioeconômica, somada à crescente organização dos segmentos populares - particularmente os trabalhadores e, inclusive, as mulheres -, além do impacto trazido no Ocidente pela Primeira Guerra Mundial, tudo contribuiu para que aflorasse o fenômeno da constitucionalização dos direitos sociais e do próprio Direito do Trabalho (a par da constitucionalização do Direito da Seguridade Social). 
A Constituição do México (1917) e a Constituição da Alemanha (Weimar, 1919) foram as primeiras a reconhecer a liberdade de associação sindical e a inserirem certo conjunto de regras de Direito do Trabalho e de Seguridade Social em seu interior. Nesse mesmo cenário de mudanças e de inclusão social, cultural, institucional e jurídica, foi criada, também em 1919, pelo Tratado de Versalhes, a Organização Internacional do Trabalho (OIT), voltada a gerar diplomas normativos e/ou programáticos trabalhistas, incentivando a sua incorporação nas ordens jurídicas internas de seus inúmeros Estados integrantes ${ }^{7}$.

No constitucionalismo brasileiro, esse segundo paradigma foi incorporado por intermédio da Constituição de 1934, reafirmando-se com a Constituição de 1946.

Tal paradigma, conforme exposto, teve a grande virtude de romper 0 monopólio do liberalismo tradicional, inserindo questões e direitos sociais nos documentos constitucionais, além introduzir e ampliar os mecanismos democráticos na ordem institucional do Estado. Entretanto, esse novo paradigma não chegou a construir concepções novas e mais complexas sobre o próprio Direito, sobre a própria Democracia e, até mesmo, sobre o conjunto da estruturação e funcionamento do sistema socioeconômico que caracterizava, na época, há mais de um século, os países ocidentais mais desenvolvidos - isto é, o sistema capitalista. Tais avanços apenas seriam alcançados com o terceiro paradigma do constitucionalismo - o do Estado Democrático de Direito -, construído pelos documentos constitucionais europeus lavrados depois da Segunda Grande Guerra.

As Constituições dessa fase, embora muito relevantes do ponto de vista simbólico, exprimem, segundo Paulo Bonavides, "de princípio, um estado de independência, transitoriedade e compromisso" (BONAVIDES, 2011, p.231). A Constituição da Alemanha, de 1919, é exemplo expressivo dessa marca de crise e de transitoriedade, segundo Bonavides: "A Constituição de Weimar foi fruto dessa

\footnotetext{
7 Para se compreender o impacto da criação da OIT no imaginário da política, das relações sociais e do Direito dessa época inicial do século XX, basta mencionar que a entidade internacional instituída em 1919 aprovou, até 1930, aproximadamente 30 Convenções Internacionais do Trabalho e, até 1940, no total, aproximadamente 60 Convenções Internacionais do Trabalho - documentos de natureza normativa, caso ratificados pelos respectivos Estados. Isso sem contar os documentos denominados de "Recomendações" - estes, de caráter eminentemente programático -, em número similar aos das Convenções da OIT.
} 
agonia: o Estado Liberal estava morto, mas o Estado social ainda não havia nascido" (BONAVIDES, 2011, p.233).

Na mesma linha, é o que explicita Mauricio Godinho Delgado (2012, p.43):

O Estado Social de Direito é, entretanto, de fato, apenas um modelo jurídico e político de transição, uma fase intermediária do constitucionalismo; é expressão de uma crise no paradigma originário, sem que se tenha ainda construído, com plenitude, novo, próprio e sofisticado paradigma, com a complexidade de instituições, princípios, regras e práticas sistematizadas convergentes. De fato, esse padrão constitucional, embora tenha superado aspectos importantes do período precedente, ainda não conseguia expressar um real paradigma novo de estrutura das constituições.

Embora o segundo marco do constitucionalismo tenha cumprido papel histórico, político, institucional, jurídico e filosófico importantíssimo, ao romper com a hegemonia mais do que centenária do velho liberalismo, não teve, evidentemente, o condão de criar e desenvolver conceitos e institutos mais sofisticados e complexos na direção convergente do caráter social e humanista do Direito. Essa tarefa ainda mais inovadora e também hercúlea somente seria realizada depois do término da Segunda Guerra Mundial, no contexto do novo paradigma do constitucionalismo então inaugurado na Europa Ocidental.

\subsubsection{O Estado Democrático de Direito}

A análise do terceiro paradigma do constitucionalismo - deflagrado, na Europa Ocidental, logo depois da Segunda Grande Guerra - será subdividida em dois tópicos. De uma parte, a formação do Estado Democrático de Direito, com suas características mais notáveis (muitas delas, aliás, foram responsáveis pelo outro epíteto igualmente atribuído a esse paradigma, qual seja, Constitucionalismo Humanista e Social). De outra parte, as adversidades e os desafios que se têm levantado, nos últimos 40/45 anos, contra o paradigma constitucional do Estado Democrático de Direito. 


\subsubsection{Formação do Estado Democrático de Direito e suas Características}

Com o flagelo da Segunda Guerra Mundial (1939-1945), a comunidade internacional sentiu a necessidade de criar mecanismos que pudessem garantir paz duradoura entre Estados e nações e, ao mesmo tempo, impedir o retrocesso às atrocidades cometidas pelos regimes totalitários - cujo paroxismo foram as experiências nazifascistas. A Organização das Nações Unidas (ONU) foi instituída, em 1945, com esse intento, incorporando, inclusive, a OIT - originalmente criada pelo Tratado de Versalhes de 1919 - como a sua primeira agência especializada.

Também nesse período ocorreu um aprofundamento e ampliação do processo de constitucionalização dos direitos sociais, a partir de duas direções combinadas. Em primeiro lugar, mediante a consagração da concepção normativa dos princípios jurídicos (em si, uma enorme novidade desse terceiro paradigma do constitucionalismo), acompanhada da incorporação, às novas constituições promulgadas nesse período, de diversos princípios de forte influência no campo justrabalhista - como o da dignidade da pessoa humana, da subordinação da propriedade à sua função social, da valorização do trabalho e especialmente do emprego, da justiça social, da igualdade em sentido substancial (em acréscimo à igualdade em sentido formal) e da centralidade do ser humano na ordem jurídica, a par de outros princípios.

De outro lado, por meio do alargamento do conceito de cidadania, com o conseqüente redimensionamento da própria concepção de direitos individuais e sociais, ampliando-os de maneira a abranger não apenas os essenciais mundos do trabalho e da seguridade social, com também a educação, a saúde, a moradia, o transporte de massas, a cultura e o lazer, ilustrativamente. Essa inusitada quadra de avanços civilizatórios deu origem a uma verdadeira "era de direitos", conforme bem enfatizado por Norberto Bobbio (2004).

Todas essas notáveis conquistas e modificações - qualitativas e, ao mesmo tempo, quantitativas - implicaram, por decorrência lógica, uma nova visão sobre o Direito e sobre o próprio sistema capitalista no mundo ocidental, em particular no ocidente europeu. 
A nova visão englobou a economia e a gestão da sociedade. Nessa medida, conforme enfatiza Gabriela Neves Delgado (2012, p.24):

[...] a instauração de um Estado forte e intervencionista, capaz de garantir direitos e restabelecer a economia, foi a alternativa encontrada pelos países do capitalismo central para sobreviverem à devassa da sangrenta Segunda Grande Guerra Mundial e resgatarem, sob nova ótica, a dinâmica capitalista.

A intervenção do Estado, com suas políticas protecionistas e de equidade, representou a solução para preservar o sistema capitalista, impondo limites à liberdade individual, tendo em conta a necessidade de reestruturação da economia e da própria sociedade. A vontade individual livre e incontrastável - um dos elementos mais caros ao antigo Estado Liberal de Direito, pilar dos conceitos jurídicos de liberdade contratual e de propriedade privada (e, assim, de livre iniciativa) - passou a ser posta em equilíbrio perante as necessidades e os objetivos sociais e coletivos, os quais passaram a ser considerados também relevantes na vida socioeconômica.

Nesse cenário, a partir de meados do século XX - mais especificamente, logo depois da Segunda Grande Guerra -, legitimou-se o paradigma do Estado Democrático de Direito mediante a generalização dos direitos de segunda dimensão (sociais, econômicos, coletivos e culturais) - os quais tiveram a sua primeira incorporação, embora meramente parcial (direitos trabalhistas e previdenciários), no constitucionalismo social da segunda década do século XX. Na verdade, esse largo rol de direitos de segunda dimensão não representou uma ruptura com os direitos de primeira dimensão mas, sim, um redimensionamento do paradigma liberal sob a lente da responsabilidade social ${ }^{8}$.

A fase histórica seguinte à Segunda Guerra Mundial foi exatamente o período de maior expansão do Direito do Trabalho, cujo fundamento medular é a limitação da vontade meramente individual - veículo que propicia a matriz notoriamente democrática e distributiva de renda desse campo jurídico especializado. Em linha similar, o Direito da Seguridade Social.

\footnotetext{
8 "Nesse contexto, o Estado tornou-se um Estado Administrador, intervencionista e assistencialista, o cidadão, um 'cidadão-cliente'". DELGADO, 2012, p. 25.
} 
Uma das maiores conquistas civilizatórias do paradigma do Estado Democrático de Direito foi o denominado Estado de Bem-Estar Social (também denominado Estado Providência ou Welfare State) - uma estrutura de sociedade política e de sociedade civil que se disseminou em alguns países da Europa Ocidental após a Segunda Grande Guerra, preservando-se até a atualidade, em maior ou menor grau, principalmente na Escandinávia (Suécia, Dinamarca, Noruega e Islândia), além da Alemanha e França. Esse modelo funda-se em um intervencionismo estatal combinado com o dinamismo do mercado econômico privado, objetivando elevar as condições de vida e de trabalho de suas populações, eliminando a pobreza e reduzindo as desigualdades sociais. No Welfare State, a justiça social passa a permear a atuação do Estado por intermédio de políticas públicas universais, garantidoras de direitos e redistributivas de renda. Tais políticas públicas mostram-se muito presentes não apenas no campo do trabalho e emprego, a par da Seguridade Social (campos em que foram pioneiras, desde o paradigma constitucional imediatamente anterior), como também em outros segmentos relevantes, como a educação, a saúde, o transporte de massas, a moradia, a cultura, o lazer etc. ${ }^{9}$.

A amplitude e a densidade da nova fase constitucional a tem feito merecer também o epíteto sugestivo de Constitucionalismo Humanista e Social' ${ }^{10}$.

Nas reflexões de Cristiano Paixão, a tônica desse novo paradigma estatal é a ideia de "compensação" a uma grande camada de indivíduos despossuídos, diante da concentração de riqueza e poder em alguns setores específicos da sociedade. Essa "compensação" se viabilizou por meio de uma rede de proteção. O Estado passou a atrair para si a tarefa de prover compensação e inclusão. Ocorre que do encargo provedor resultou exponencial crescimento das competências do Estado (PINTO, 2003, p.40).

\footnotetext{
9 Sobre o Estado de Bem-Estar Social, consultar as seguintes obras: 1) CONDÉ, 2008; 2) DELGADO, 2017; 3) DELGADO; PORTO, 2007; 4) KERSTENETZKY, 2012; 5) KRISTENSEN; LILJA, 2011; 6) PIKETTY, 2014; 7) PIERSON, 2006; 8) WILKINSON, 2015.

10 Mauricio Godinho Delgado refere-se a esse paradigma pelas duas denominações, sem distinção entre elas. Assim, faz uso tanto do epíteto "paradigma do Estado Democrático de Direito" como da expressão "paradigma do Constitucionalismo Humanista e Social". A respeito, consultar, por exemplo, seu livro 2017c, p. 42.
} 
A par desse indubitável aumento das atribuições estatais, tal modelo constitucional, entretanto, igualmente alargou as atribuições do sistema econômico capitalista, a ele determinando um conjunto de regras e princípios jurídicos voltados à elevação e ao aperfeiçoamento da contratação e gestão da força de trabalho na vida social e econômica. Também as empresas capitalistas, ao invés de somente o Estado, passaram a participar do novo paradigma constitucional inclusivo e democrático, com a necessária garantia de melhores condições de trabalho e de renda para todo o segmento dos trabalhadores, sejam eles provindos de qualquer setor da economia, como o industrial, o comercial, o financeiro, o de prestação de serviços, o rural ou qualquer outro. Na dimensão de atuação do Estado Democrático de Direito, o campo justrabalhista cumpriria papel decisivo.

No constitucionalismo brasileiro, o paradigma do Estado Democrático de Direito foi incorporado por intermédio da Constituição da República de cinco de outubro de 1988, alguns anos depois do encerramento da experiência autocrática desempenhada pelo regime militar-civil de 1964 a 1985.

Conforme visto, na dinâmica do processo histórico, o paradigma do Estado Democrático de Direito emerge para aperfeiçoar os paradigmas anteriores, mas não no sentido de negá-los, por inteiro, ou deslegitimá-los, por inteiro. Os direitos e garantias de primeira e de segunda dimensões passam por um processo de releitura e adequação de seu alcance e conteúdo ao novo modelo.

Assim, os direitos e garantias de primeira dimensão passam a ostentar caráter, formato e objetivos mais pluralistas, sociais e universais, perdendo o viés meramente individualista e elitista que os caracterizara no Estado Liberal de Direito. É claro que a extensão dessa releitura e adequação fica na dependência do processo histórico-político inerente a cada país, sendo mais firmemente avançado nos países nórdicos, enquanto se evidencia mais modesto nos países europeus mediterrâneos e ibéricos. Na América Latina, tais avanços, lamentavelmente, têm sido ainda muito mais restritos do que os verificados na Europa Ocidental, embora, em comparação com o processo histórico latinoamericano específico, tenham sido também relevantes (ilustrativamente, o período sob regência da Constituição de 1988, no Brasil, em comparação com o período constitucional anterior). 
De igual modo, os direitos e garantias de segunda dimensão se generalizam e se aprofundam no Constitucionalismo Humanista e Social posterior à Segunda Grande Guerra, elevando, de maneira substancial, as condições de vida e trabalho das populações europeias favorecidas. Se não bastasse, como dito, os direitos trabalhistas e previdenciários foram acompanhados por novos direitos individuais e sociais, tais como os vinculados ao transporte de massas, à moradia, à saúde, à educação, à cultura e ao lazer.

Nesse novo paradigma também afloram os denominados direitos de terceira dimensão, pautados na fraternidade e solidariedade universais. Entre eles se englobam, por exemplo, o direito à paz, à justiça social como um valor universal, à solidariedade (considerados os seus inúmeros aspectos), o respeito ao meio ambiente, à pluralidade, às minorias e ao multiculturalismo, a par do respeito à autodeterminação dos povos.

É nesse novo paradigma constitucional que também se desenvolve o conceito de direitos difusos, coletivos e individuais homogêneos, com a correspondente matriz direcionada às tutelas processuais metaindividuais (PIMENTA, 2009, p.9-50).

Em síntese, no paradigma do Constitucionalismo Humanista e Social - o paradigma do Estado Democrático de Direito -, a democracia não mais se limita a seu aspecto formal, evoluindo para ser pensada, estruturada e operada de maneira inclusiva, a fim de viabilizar a igualdade substancial em suas diversas vertentes: política, institucional, social, econômica, jurídica e cultural.

Vale ressaltar que, no precedente Estado Social de Direito, a democracia representativa já passara a existir, em face da incorporação de direitos e perspectivas inerentes às camadas mais amplas da população, ao invés de apenas inerentes às elites (de que são exemplos os direitos individuais e sociais trabalhistas e previdenciários, além da universalização do voto, iniciada já na segunda fase do constitucionalismo, em alguns países).

Mas o fato é que, no Estado Social de Direito, essa concepção de democracia ainda não era plena e nem multidimensional, ao mesmo tempo em que a inserção social dos direitos na seara constitucional ainda se fazia de forma tímida e limitada. De outra parte, os princípios jurídicos, se já apareciam - embora 
esparsamente - nos então novos textos constitucionais, limitavam-se a um sentido meramente formal e, em boa medida, como simples postulados programáticos.

Ou seja, o segundo paradigma do constitucionalismo apontava para um processo de democratização da sociedade, sem dúvida (e, nesse aspecto, superava firmemente o paradigma liberalista); porém, ainda não apresentava uma complexidade de instrumentos e instituições para essa democratização. No novo paradigma do Estado Democrático de Direito, todas essas limitações são manifestamente superadas.

$\mathrm{Na}$ Constituição Brasileira de 1988 , os direitos sociais, inclusive os trabalhistas, passam a compor o núcleo da nova Constituição da República - ao invés de serem apenas seu apêndice, como próprio dos textos constitucionais inaugurados nas décadas de 1930 e de 1940. Em 1988, efetivamente, elege-se o trabalho digno como direito fundamental e universal, ao passo que os direitos trabalhistas são incorporados ao estuário superior dos direitos e garantias individuais e sociais fundamentais (Título II da CF/88). Como a razão de ser do Direito do Trabalho é justamente a proteção do "valor trabalho" para o alcance da justiça social ${ }^{11}$, daí decorre a indisponibilidade dos direitos trabalhistas, como regra geral, inclusive constitucional.

No plano da nova Constituição de 1988, o sistema jurídico passa a se orientar pela dignidade da pessoa humana, diretriz cardeal de todo o ordenamento jurídico. Nesse contexto, justifica-se a supremacia dos direitos fundamentais, inclusive os individuais e sociais trabalhistas, com a sua intangibilidade ${ }^{12}$. Conforme se percebe, o período histórico do Estado Democrático de Direito marca a passagem, inclusive no Brasil da Constituição de 1988, da concepção jurídica individualista para a visão humanista, sistêmica e intersubjetiva entre o indivíduo e seus pares, em dimensão plural e social.

11 Sendo fundamentos da República Federativa do Brasil constituída em Estado Democrático de Direito os valores sociais do trabalho e da livre iniciativa, ao lado da dignidade da pessoa humana, como expressamente dispõe o artigo $1^{\circ}$ da Constituição de 1988, em seus incisos III e IV. Paralelamente, o artigo 3을 desta mesma Norma Fundamental estabelece de forma explícita, no caput e em seus incisos I e III, que construir uma sociedade livre, justa e solidária e erradicar a pobreza e a marginalização e reduzir as desigualdades sociais e regionais são objetivos fundamentais da República Federativa do Brasil.

${ }^{12}$ Chegando esses direitos fundamentais (em geral) a ser protegidos, pelo próprio texto constitucional (art. 60, § $4^{\circ}$ ), pela atribuição, aos mesmos, da condição de cláusula pétrea, que não pode sequer ser objeto de proposta de emenda constitucional que vise sua abolição. 
$\mathrm{Na}$ seara do contratualismo, a vontade individual cede lugar ao interesse social. A ética da solidariedade substitui a ética do individualismo. Sob esse paradigma, as empresas possuem direitos e obrigações, a par de deveres, inclusive. A máxima neminem laedere, que corresponde ao dever de não lesar ninguém e não contrariar o direito de outrem (art. 186 do Código Civil), passa a englobar, claramente, não só as pessoas físicas, mas também as pessoas jurídicas, no sentido de lhes ser vedado causar danos aos trabalhadores e ao meio-ambiente ${ }^{13}$.

Aprimora-se o conceito de igualdade material/substancial, em face das agudas desigualdades sociais e regionais a serem enfrentadas, por força do já citado mandamento constitucional. O Estado deve não só observar os direitos fundamentais consagrados na ordem jurídica, como também zelar pela sua efetivação, garantindo que sejam observados também no âmbito da sociedade civil.

A partir do pressuposto da eficácia horizontal dos direitos fundamentais (muito além de sua simples eficácia vertical, perante o Estado), a violação de um direito fundamental (o direito ao trabalho digno, por exemplo) não se limita à relação entre o Estado e o(s) indivíduo(s); ao invés, passa a abranger também as relações jurídicas entre os particulares, inclusive e especialmente as relações assimétricas de poder, tal como a relação empregatícia ${ }^{14}$. A função do Estado não mais se restringe à proteção dos direitos fundamentais, evoluindo para assegurar, por meio de condutas efetivas, inclusive no plano jurisdicional ${ }^{15}$, que os direitos fundamentais sejam respeitados e cumpridos por todos, assumindo um papel de regulador das relações sociais. Nesse quadro, não observadas as normas justrabalhistas de modo espontâneo, nasce para o Estado o poder-dever de agir em prol de uma sociedade mais inclusiva, com a garantia de condições mínimas de dignidade a todos os seus integrantes.

\footnotetext{
${ }^{13}$ É o que apontam com propriedade os autores SOUTO MAIOR; MOREIRA; SEVERO, 2014, p. 27.

14 Sobre a eficácia dos direitos fundamentais nas relações jurídicas entre particulares (a denominada eficácia horizontal dos direitos fundamentais), vejam-se SARLET, 2007, p. 398-406; VIEIRA DE ANDRADE, 2006, p. 246-281; PEREIRA, 2006, p. 431-497; BARROSO, 2006, p. 119-192; SARMENTO, 2006, p. 193-284 e MARINONI, 2004, p. 169-175.

${ }^{15}$ Sobre o tema do acesso à justiça em geral, consultem-se CAPPELLETTI; GARTH, 1988, p. 7-15 e 161-165; MARINONI, 1999, p. 20-37. Ainda sobre o acesso à Justiça como direito fundamental e garantia primeira da existência e da efetividade da própria Constituição ("o direito aos direitos"), vejase, por todos, o trabalho de ROCHA, 1993, p. 31-51.
} 
2.2.3.2 Adversidades e Desafios Levantados Contra o Estado Democrático de Direito

O paradigma do Constitucionalismo Humanista e Social, nos últimos 40/45 anos, passou a sofrer, no mundo ocidental, desde o transcorrer dos anos de 1970, uma série de adversidades, com maior ou menor força em conformidade com as peculiaridades históricas dos distintos países e Estados envolvidos. Tais adversidades, embora ostentando natureza variada, apresentam em comum o fato de coincidirem com a retomada da hegemonia ideológica do velho liberalismo no Ocidente - agora rebatizado pelo epíteto de neoliberalismo.

Não se trata de dizer que todos os fatores desgastantes ou desafiadores surgidos possam ser englobados no interior da vertente neoliberal. De forma alguma; apenas se trata de perceber a sagacidade com que tal corrente de pensamento, na construção de sua hegemonia ao longo das últimas décadas, tem organizado e direcionado argumentos para o processo de desgaste do Constitucionalismo Humanista e Social, brandindo, em contraponto, as suas propostas incessantes de corte ou descaracterização de políticas públicas inclusivas e distributivas, a par do corte de direitos individuais e sociais, todos identificados como características fundamentais do terceiro paradigma do constitucionalismo.

De fato, ao longo da década de 1970, deflagrou-se no Ocidente uma repentina e grave crise econômica, inicialmente provocada pela elevação do processo inflacionário na economia, em vista do abrupto crescimento do preço do petróleo provocado pela OPEP, no contexto das disputas políticas e territoriais incessantes ocorridas no Oriente Médio (1973/1974: o "choque do petróleo"). Imediata e profunda recessão econômica se instaurou no Ocidente, com a perda do dinamismo da economia privada e da arrecadação tributária dos respectivos Estados. Nesse quadro de grave e repentina crise econômica, as atenções se dirigiram aos inúmeros compromissos e endividamentos do setor público, encorpados pelos gastos decorrentes do Welfare State. Tal quadro de adversidades econômicas e financeiras concentradas desencadeou a crise conjuntural do Estado de Bem-Estar Social (crise fiscal do Estado), a par de abrir espaço largo para a emergência de propostas e ideários adversos, sintetizados, nas últimas décadas, 
pela corrente política, econômica e ideológica conhecida como neoliberalista (neoliberalismo e/ou ultraliberalismo) ${ }^{16}$.

A falta de aptidão dos governos sociaisdemocratas então dominantes na Europa Ocidental em conferir rápida e eficiente resposta aos desafios da crise econômica despontada, com os seus efeitos socioeconômicos deletérios (deterioração e/ou fechamento de empresas; elevação do desemprego; diminuição da arrecadação tributária do Estado, entre outras repercussões), tudo conduziu a um novo contexto propiciador de vitórias eleitorais decisivas de lideranças políticas ultraliberalistas, em países líderes do capitalismo ocidental: Grã Bretanha, em 1979 (Margareth Thatcher: governo de 1979 até 1990); EUA, em 1982 (Ronald Reagan: governo de 1981 até 1989); Alemanha, em 1982 (Helmut Kohl: governo de 1982 até 1998). Agregue-se que o encerramento do mandato desses líderes originários do ultraliberalismo não pôs fim ao processo de reconstrução da hegemonia liberalista no Ocidente, pois os partidos ou coligações conservadoras mantiveram-se no poder, em alguns países, sob outras lideranças (por exemplo, John Major, na GrãBretanha: de 1990 a 1997; George Bush, nos EUA, de 1989 a 1993) ${ }^{17}$.

A hegemonia neoliberal estruturada, na época, passou a preponderar, firmemente, no campo das políticas econômico-financeiras, a partir de uma uniformidade de orientações dos Bancos Centrais dos principais países do Ocidente (uniformidade em torno das políticas monetaristas), a par das burocracias estatais responsáveis pelo segmento econômico-financeiro das políticas públicas. Tal uniformidade foi também impulsionada pelas principais agências internacionais de financiamento e interrelações no campo ocidental das economias, tais como o Banco Mundial, o Banco Interamericano de Desenvolvimento (BIRD), o Fundo Monetário Internacional (FMI), a Organização Mundial do Comércio (OMC), entre outras instituições internacionais. No caso dessas agências internacionais, a

${ }^{16}$ Sobre o processo de crise do Welfare State, iniciado na década de 1970 e em continuidade até os dias atuais, consultar, por exemplo: ASSIS, 2002; CHESNAIS, 1998; DELGADO, 2017a. HOBSBAWN, 1995; PINTO, 2003.

17 Todo esse cenário está descrito em DELGADO, 2017a, p. 25-30; p. 68-74 e 77-101. Registre-se, a propósito - conforme adiantado -, que, mesmo após o encerramento dos mandatos desses líderes políticos iniciais do ultraliberalismo no Ocidente, reproduziram-se, no poder político, em distintos Estados Ocidentais, lideranças também filiadas ao pensamento neoliberal já hegemônico. Pior do que isso, algumas lideranças sociaisdemocraticas passaram a aderir, em parte, à perspectiva neoliberalista, contribuindo para fustigar o Estado de Bem-Estar Social, pilar fático decisivo do Constitucionalismo Humanista e Social. 
uniformidade se dava em torno de uma agenda sistematizada de políticas públicas ultraliberalistas para os diversos países e economias sob sua influência ${ }^{18}$.

Todas essas orientações, diretrizes e novas políticas públicas focavam, por exemplo, o aprofundamento das restrições monetárias; o contingenciamento do crédito na economia; o corte dos subsídios em favor de setores mais vulneráveis, sejam econômicos, sejam sociais; a atenuação dos tributos direcionados às empresas e aos segmentos socioeconômicos mais abastados na pirâmide social; a diminuição da participação do Estado nas atividades da economia e da sociedade; a desregulamentação generalizada da ordem jurídica dirigida à sociedade, à economia e às relações socioeconômicas, inclusive e especialmente, as relações socioeconômicas assimétricas, inclusive as trabalhistas e previdenciárias; o incremento da livre concorrência internacional no espaço interno das economias nacionais, entre outras medidas.

O fato é que, em seu conjunto, tais diretrizes diminuíam o ímpeto da economia, elevavam a concentração de renda, acanhavam as políticas sociais, instigavam a precarização do Direito do Trabalho e do Direito da Seguridade Social - em suma, fustigavam as bases de estruturação, desenvolvimento e atuação do Estado de Bem-Estar Social, pilar fático de concretização do Constitucionalismo Humanista e Social e do próprio Estado Democrático de Direito, em seu formato multidimensional ${ }^{19}$.

Esse contexto de reestruturação hegemônica no Ocidente coincidiu também com uma reestruturação tecnológica no sistema capitalista - a chamada terceira revolução tecnológica e, atualmente, até mesmo a alegada quarta revolução tecnológica -, cujas bases e tendências, sem o contraponto de políticas públicas

\footnotetext{
${ }^{18}$ A influência do neoliberalismo somente tem sido hegemônica no Ocidente, não apresentando a mesma força nas burocracias e governos dos países asiáticos (salvo quanto ao Banco Central do Japão, a partir de finais dos anos de 1970). A respeito, consultar DELGADO, 2017a, p. 68-113.

19 Sobre o sentido antissocial e, até mesmo, antidemocrático da agenda de políticas públicas inerentes ao ultraliberalismo, consultar DELGADO, 2017a, especialmente o Capítulo III ("Capitalismo Sem Reciprocidade: a política pública de destruição do emprego"), p. 68-113. Registre-se que, com a crise capitalista ocidental deflagrada em 2008, a partir dos EUA, atingindo, inclusive, os países europeus, os governos da União Europeia e seu respectivo Banco Central relaxaram a política monetária e creditícia, como mecanismo de salvamento do sistema bancário e de reativação da economia. Porém, ao invés de realizarem a subsequente e lógica cobrança, após debelado o núcleo da crise, dos gastos estatais efetuados sobre o sistema bancário que fora altamente favorecido, decidiram aprofundar as políticas neoliberais de degradação dos direitos sociais, com reformas previdenciárias e trabalhistas de grave sentido precarizador em distintos países europeus.
} 
regulatórias e compensatórias, exacerbam o quadro de desagregação dos campos jurídicos protetivos do Constitucionalismo Humanista e Social, como o Direito do Trabalho, o Direito da Seguridade Social, o Direito Ambiental, entre outros campos de políticas públicas de caráter inclusivo, democrático e social.

As novas revoluções tecnológicas, em si mesmas, não teriam o condão de desestruturar o Constitucionalismo Humanista e Social. Poderiam, sem dúvida, provocar a necessidade de certos ajustes e adaptações, porém sem a força e o sentido de descaracterizarem o paradigma do Estado Democrático de Direito.

Entretanto, ocorridas no contexto de uma hegemonia disruptiva das políticas sociais, inclusivas e democráticas, tais revoluções tecnológicas, sem dúvida, passaram a se tornar mais um argumento brandido, com notável força ideológica, em direção à desconstrução das bases de organização e funcionamento do terceiro paradigma do constitucionalismo.

São adversidades e desafios que se antepõem, sem dúvida, ao paradigma do Constitucionalismo Humanista e Social. Mas não são desafios e adversidades que indicam, necessariamente, o ocaso desse paradigma, a sua inevitável destruição. $\mathrm{Na}$ verdade, apenas demonstram a urgência de as Constituições vigorantes, com seu humanismo e sua perspectiva social, voltarem a preponderar sobre os interesses e desígnios da ordem econômica na História Contemporânea.

\subsection{O ESTADO DEMOCRÁTICO DE DIREITO COMO MARCO CONTEMPORÂNEO DO CONSTITUCIONALISMO}

A concepção de Estado Democrático de Direito, como o próprio nome revela, pressupõe a escolha constitucional em favor da democracia, em sua conformação participativa e inclusiva, envolvendo todos os atores sociais nas mais diversas perspectivas: política, social, econômica, cultural, jurídica e institucional. Nesse quadro, a característica diferenciadora do Estado Democrático de Direito reside na percepção do Direito como instrumento civilizatório, ao invés de instrumento de exclusão e segregação. A Constituição Federal de 1988 é fruto desse paradigma democrático e inclusivo. 
A expressão "democrático" não constitui uma simples alusão à democracia representativa, enquanto parte da perspectiva política da ideia de democracia embora também a englobe. Sua abrangência envolve as múltiplas dimensões do fenômeno democrático, quer as políticas, as econômicas, as sociais, as institucionais, as jurídicas e as culturais. Envolve, portanto, a garantia dos direitos individuais e sociais fundamentais na promoção de uma sociedade livre, equânime (igualdade em sentido substancial), justa e solidária. Abrange, pois, o direito à saúde, à educação, ao trabalho digno e particularmente ao emprego, à Seguridade Social, à alimentação, ao transporte massivo de qualidade, à moradia, à cultura, ao lazer, entre outros. Direitos que estão em linha, a propósito, com o propugnado pelo art. 6o da Constituição Federal de 1988. Nesse contexto, o Estado Democrático de Direito não se refere a uma concepção restrita de democracia formal, meramente representativa, porém à ideia de democracia multidimensional.

Esse novo paradigma desenvolve-se em torno da complexidade das relações sociais, impulsionando novas manifestações de direitos, como os relacionados, inclusive - além do já exposto -, à tutela do meio ambiente, aos interesses difusos e às reivindicações de grupos minoritários antes ausentes do processo democrático. Uma das ênfases desse novo paradigma constitucional direciona-se para a ideia ampliada de cidadania (cidadania ampliada), compreendida em sua dimensão também multidimensional.

Nesse sentido, há de se compreender a lição de Mauricio Godinho Delgado, no sentido de que o Estado Democrático de Direito inaugura um novo constitucionalismo, humanista e social. Para o autor, o Estado Democrático de Direito estrutura-se em um inovador tripé conceitual: "a pessoa humana, com sua dignidade; a sociedade política, concebida como democrática e inclusiva; e a sociedade civil, também concebida como democrática e inclusiva"20.

Esse tripé conceitual inovador encontra previsão no já citado art. 1ํㅡ, caput, da Constituição Federal, a par do importante e harmônico conjunto de princípios constitucionais humanísticos e sociais que Ihe conferem suporte. Veja-se, a esse respeito, $\mathrm{O}$ art. $1^{\circ}$ da CF:

20 DELGADO, 2014, p. 161. O artigo citado foi originalmente publicado, como Capítulo III, na obra dual de DELGADO; DELGADO, 2012. 


\begin{abstract}
Art. 1ํ A República Federativa do Brasil, formada pela união indissolúvel dos Estados e Municípios e do Distrito Federal, constitui-se em Estado Democrático de Direito e tem como fundamentos: (...) I - a soberania; II - a cidadania; III - a dignidade da pessoa humana; IV - os valores sociais do trabalho e da livre iniciativa; V - o pluralismo político. (...) Parágrafo único. Todo o poder emana do povo, que o exerce por meio de representantes eleitos ou diretamente, nos termos desta Constituição.
\end{abstract}

Notem-se, ilustrativamente, alguns desses princípios constitucionais humanistas e sociais de indução e suporte ao Estado Democrático de Direito: 1) dignidade da pessoa humana; 2) centralidade da pessoa humana na ordem jurídica e na vida socioeconômica; 3) inviolabilidade do direito à vida; 4) respeito à privacidade e à intimidade; 5) valorização do trabalho e especialmente do emprego; 6) justiça social; 7) não discriminação; 8) subordinação da propriedade à sua função socioambiental; 9) igualdade em sentido substancial (ao invés de apenas em sentido meramente formal); 10) segurança, em seu novo caráter multidimensional; 11) bemestar individual e social; 12) princípio da proporcionalidade; 13) princípio da vedação do retrocesso social ${ }^{21}$.

O novo marco do constitucionalismo afirma-se como cenário e instrumento para a realização mais ampla da liberdade e da igualdade, da dignidade da pessoa humana e do conteúdo democrático e inclusivo dos direitos individuais, sociais e políticos. O cidadão é reconhecido como sujeito ativo e, ao mesmo tempo, destinatário das políticas públicas, ao passo que a democracia deixa de ser um conceito apenas formal, limitado ao Estado e suas instituições, para se mostrar presente também no âmbito da vida social privada. Conforme já exposto, no terceiro paradigma do constitucionalismo não apenas a sociedade política tem de ser democrática e inclusiva, como igualmente a sociedade civil, com as suas instituições, inclusive as econômicas, tem de ser democrática e inclusiva (DELGADO; DELGADO, 2017).

Pode-se afirmar que apenas no paradigma do Estado Democrático de Direito a democracia atinge seu o conceito largamente inovador, inclusivo e substancial. É que, no Estado Liberal de Direito, a ideia de democracia, quando referenciada, era

21 Tais princípios humanistas e sociais estão arrolados, por exemplo, em duas obras: DELGADO, Mauricio Godinho; DELGADO, 2013 (a referida coleção é constituída de três volumes). Igualmente: DELGADO, 2017c, especialmente em seu Capitulo II (“Princípios Constitucionais do Trabalho"), p. 36 100. 
compreendida de modo excludente, uma vez que dirigida apenas às elites proprietárias. Sem dúvida, conquistas importantes ocorreram naquele primeiro marco do constitucionalismo, como o reconhecimento das liberdades individuais formais de opinião, de locomoção, de reunião, de manifestação do pensamento, de manifestação coletiva. Tais liberdades formais representaram, reconheça-se, o nascedouro, o primeiro passo para a construção do conceito atual de democracia embora estivessem ainda longe do conceito amplo, substantivo e multidimensional de democracia.

O Estado Social de Direito - segundo marco do constitucionalismo -, por sua vez, apontou para um importante processo de democratização no âmbito da sociedade civil e política. Nessa fase é que a ideia de democracia começa a deixar de ser inerente apenas ao plano político-institucional para iniciar sua caminhada para o campo das esferas da sociedade civil e suas instituições. Desnecessário relembrar que foi nesse período que se iniciou a incorporação, pelo Direito Constitucional, das preocupações e direitos voltados a camadas populacionais mais amplas, como os direitos trabalhistas e previdenciários.

Contudo, será realmente apenas no terceiro paradigma do constitucionalismo, do Estado Democrático de Direito - deflagrado na Europa Ocidental logo após o término da Segunda Grande Guerra -, que acontecerá a incorporação, com amplitude, do fenômeno democrático, em sua multidimensionalidade, e da relevância da perspectiva humanista e social no contexto das novas Constituições estruturadas (DELGADO, 2014, p.154-158).

No novo paradigma, há a redefinição do papel do Estado, que passa a tratar não apenas dos interesses estritamente estatais, porém igualmente da tutela dos direitos individuais e sociais da pessoa humana, agora tida como construtora, partícipe e beneficiária do novo conceito de Estado Democrático de Direito. Nesse novo paradigma constitucional, a esfera pública ostenta também o propósito de proteção do cidadão detentor de direitos fundamentais - o que não pode ser confundido com interesse meramente estatal. Há, portanto, uma reconstrução da concepção do público e do privado, o que implica a releitura desse binômio a partir do conceito de democracia inclusiva (LOBATO, 2014, p.46). 


\section{CONCLUSÃO}

O paradigma constitucional do Estado Democrático de Direito consiste no patamar civilizatório mais elevado já alcançado pelo Direito Constitucional e pelo próprio fenômeno jurídico, genericamente considerado, ao longo da História Ocidental.

Suas conquistas, características e realizações espraiam-se por diversos países, particularmente os europeus ocidentais, cujas ordens jurídicas e respectivas sociedades políticas e sociedades civis absorveram seus princípios, institutos e regras de profundo sentido humanista, social e civilizatório.

No Brasil, esse paradigma foi assumido a partir da Constituição da República promulgada em cinco de outubro de 1988.

As adversidades e os desafios antepostos ao paradigma do Constitucionalismo Humanista e Social, despontados no Ocidente desde meados da década de 1970, têm se aprofundado ao longo do tempo, fazendo-se presentes em distintas experiências históricas e nacionais.

Tais desafios e adversidades, contudo, apenas tornam mais clara a superioridade do patamar civilizatório mínimo garantido pelo terceiro paradigma do constitucionalismo no desenvolvimento histórico contemporâneo.

\section{REFERÊNCIAS}

ASSIS, J. Carlos de. Trabalho como Direito - fundamentos para uma política de promoção do pleno emprego. Rio de Janeiro: Contraponto, 2002.

BOBBIO, Norberto. A Era dos Direitos. 26 tir. Rio de Janeiro: Elsevier, 2004.

BONAVIDES, Paulo. Do Estado Liberal ao Estado Social. 10. ed. São Paulo: Malheiros, 2011.

CARVALHO NETTO, Menelick de. "Requisitos paradigmáticos da interpretação jurídica sob o paradigma do Estado Democrático de Direito". Revista de Direito Comparado, Belo Horizonte, v. 3, mai., 1999.

CAPPELLETTI, Mauro; GARTH, Bryant. Acesso à justiça. Porto Alegre: Sérgio Antônio Fabris Editor, 1988. 
CHESNAIS, François (Coord.). A Mundialização Financeira - gênese, custos e riscos. São Paulo: Xamã, 1998.

CONDÉ, Eduardo A. Salomão. Laços na Diversidade - a Europa Social e o Welfare em Movimento (1992-2002). Juiz de Fora: UFJF, 2008.

DELGADO, Gabriela Neves. "Os Paradigmas do Estado Constitucional Contemporâneo". In: DELGADO, Mauricio Godinho; DELGADO, Gabriela Neves. Constituição da República e direitos fundamentais: dignidade da pessoa humana, justiça social e direito do trabalho. São Paulo: LTr, 2012a.

DELGADO, Mauricio Godinho. Capitalismo, Trabalho e Emprego - entre o paradigma da destruição e os caminhos de reconstrução. 3. ed. São Paulo: LTr, $2017 a$.

. "Constituição da República, Estado Democrático de Direito e Direito do Trabalho". In: DELGADO, Mauricio Godinho; DELGADO, Gabriela Neves. Constituição da República e direitos fundamentais: dignidade da pessoa humana, justiça social e direito do trabalho. São Paulo: LTr, 2012b.

. "Constituição da República, Estado Democrático de Direito e Direito do Trabalho". In: DELGADO, Mauricio Godinho; DELGADO, Gabriela Neves. Constituição da República e direitos fundamentais: dignidade da pessoa humana, justiça social e direito do trabalho. 4. ed. São Paulo: LTr, 2017b.

. "Constituição da República, Estado Democrático de Direito e Direito do Trabalho". In: Trabalho, Constituição e Cidadania: a dimensão coletiva dos direitos sociais trabalhistas. Coordenadores: Gabriela Neves Delgado e Ricardo José Macêdo de Britto Pereira. São Paulo: LTr, 2014.

- Princípios Constitucionais do Trabalho e Princípios de Direito Individual e Coletivo do Trabalho. 5. ed. São Paulo: LTr, 2017c.

; DELGADO, Gabriela Neves. "A matriz da Constituição de 1988 como parâmetro para a análise da reforma trabalhista". In: Revista do Tribunal Superior do Trabalho, São Paulo: Vol. 83, n. 3 (jul./set. 2017).

Trabalho. Vol. I. São Paulo: Editora Revista dos Tribunais, 2013.

DELGADO, Mauricio Godinho; PORTO, Lorena Vasconcelos. O Estado de BemEstar Social no Século XXI. São Paulo: LTr, 2007.

DERRIDA, Jacques. "A estrutura, o signo e o jogo no discurso das ciências humanas". Trad. de Antônio Ramos Rosa. In: COELHO, E. P. (Org.). Estruturalismo: antologia de textos teóricos. São Paulo, Martins Fontes, s.d. 1997. 
HOBSBAWN, Eric. Era dos Extremos - o breve século XX - 1914-1991. São Paulo: Companhia das Letras, 1995.

KERSTENETZKY, Célia Lessa. O Estado de Bem-Estar Social na Idade da Razão - a reinvenção do estado social no mundo contemporâneo. Rio de Janeiro: Elsevier, 2012;

KUHN, Thomas S. A estrutura das revoluções científicas. São Paulo: Perspectiva, 5. ed. 1998. Tradução: Beatriz Vianna Boeira e Nelson Boeira; Revisão: Alice Kyoto Miyashiro; Produção: Ricardo W. Neves e Adriana Garcia., p. 13. Disponível em https://leandromarshall.files.wordpress.com/2012/05/kuhn-thomas-a-estrutura-dasrevoluc3a7c3b5es-cientc3adficas.pdf Acesso em 13/10/1018.

KRISTENSEN, Peer Hull; LILJA, Kari (ed.). Nordic Capitalisms and Globalization - new forms of economic organization and welfare institutions. United Kingdom: Oxford University Press, 2011.

LOBATO, Marthius Sávio Cavalcante. A reconstrução da jurisdição constitucional: a garantia constitucional dos direitos fundamentais sociais. São Paulo: LTr, 2014.

MARINONI, Luiz Guilherme. Novas linhas do processo civil. 3. ed. rev. e atual., São Paulo: Revista dos Tribunais, 1999.

Técnica processual e tutela dos direitos, São Paulo: Revista dos Tribunais, 2004.

PEREIRA, Jane Reis Gonçalves. Interpretação constitucional e direitos fundamentais. Rio de Janeiro: Renovar, 2006.

"Apontamentos sobre a aplicação das normas de direito fundamental nas relações jurídicas entre particulares". In BARROSO, Luís Roberto (organizador), A nova interpretação constitucional: ponderação, direitos fundamentais e relações privadas, $2^{\mathrm{a}}$ edição, Rio de Janeiro: Renovar, 2006.

PIERSON, Christopher; CASTELS, Francis G. The Welfare State Reader. Second Edition. Cambridge (UK): Polity Press, 2006.

PIKETTY, Thomas. O Capital no Século XXI. Rio de Janeiro: Intrínsica, 2014;

PIMENTA, José Roberto Freire. "A Tutela Metaindividual dos Direitos Trabalhistas: Uma Exigência Constitucional". In: PIMENTA, José Roberto Freire, BARROS, Juliana Augusta Medeiros de e FERNANDES, Nadia Soraggi (coordenadores). Tutela Metaindividual Trabalhista - a defesa coletiva dos direitos dos trabalhadores em Juízo. São Paulo: LTr, 2009.

PINTO, Cristiano Paixão Araujo. Arqueologia de uma distinção: o público e o privado na experiência histórica do Direito. In: PEREIRA, Cláudia Fernanda de Oliveira. 
(Org.). O Novo Direito Administrativo Brasileiro: o Estado, as agências e o terceiro setor. Belo Horizonte: Fórum, 2003.

ROCHA, Carmen Lúcia Antunes. "Direito constitucional à jurisdição". In: TEIXEIRA, Sálvio de Figueiredo (coord.). As garantias do cidadão na Justiça, São Paulo: Saraiva, 1993.

SARLET, Ingo Wolfgang. A eficácia dos direitos fundamentais. $7^{a}$ edição. Porto Alegre: Livraria do Advogado, 2007.

SARMENTO, Daniel. "A vinculação dos particulares aos direitos fundamentais no direito comparado e no Brasil". In: A nova interpretação constitucional: ponderação, direitos fundamentais e relações privadas, $2^{\underline{a}}$ edição, Rio de Janeiro: Renovar, 2006.

SOUTO MAIOR, Jorge Luiz; MOREIRA, Ranúlio Mendes; SEVERO, Valdete Souto. Dumping social nas relações de trabalho. $2^{\mathrm{a}}$ ed. LTr: São Paulo, 2014, p. 31. EBook. ISBN: 9788536128412 . Disponível em http://www.Itreditora.com.br/e-bookdumping-social-nas-relacoes-de-trabalho-7701-5.html. Acesso em 29/12/2017.

VIEIRA DE ANDRADE, José Carlos. Os direitos fundamentais na Constituição Portuguesa de 1976, 3르 edição, Coimbra: Ed. Almedina, 2006.

WILKINSON, Richard; Pickett, Kate. O Nível - por que uma sociedade mais igualitária é melhor para todos. Rio de Janeiro: Civilização Brasileira, 2015. 